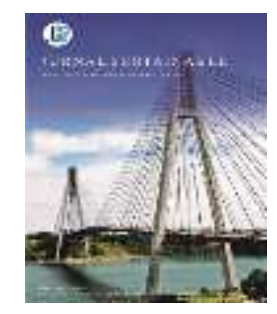

Jurnal Sustainable: Jurnal Hasil Penelitian dan Industri Terapan Vol. 07, No. 02, hal. 95-101, Oktober 2018

Jurnal Sustainable: Jurnal Hasil Penelitian dan Industri Terapan

ISSN 2615-6334 (Online) ISSN 2087-5347 (Print)

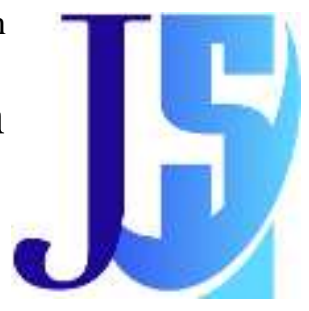

\title{
Perencanaan Kawasan Prioritas Penyediaan Air Bersih menggunakan Fuzzy Multi Criteria Decision Making
}

\author{
Angger Setia Winata ${ }^{1, *}$, Eka Suswaini ${ }^{2}$, Nola Ritha $^{3}$ \\ ${ }^{1,2,3}$ Jurusan Informatika, FakultasTeknik, Universitas Maritim Raja Ali Haji \\ ${ }^{1,2,3}$ Jl. Politeknik Senggarang, Tanjungpinang 29100 \\ *Corresponding Author: anggers666@gmail.com
}

\begin{abstract}
The Provision of water for the community, there are some problems and until now can not be overcome completely. Especially in slum areas that are prone to water so that people have difficulty to get water. Many of slums in Kab. Lingga becomes a separate problem for the planning of water supply, from the problem it is designed a system that aims to determine the priority area of water supply by implementation the fuzzy multi criteria decision making method in the planning of the priority area of water supply, obtaining the region with the highest total integral value that is Marok Tua with a value of $\alpha 0$ is $0,34375, \alpha 0,5$ is $0,51875, \alpha 1$ is 0,69375 .
\end{abstract}

Keywords: supply, priority, fuzzy, water, criteria

Intisari-Penyediaan air bersih untuk masyarakat, masih terdapat beberapa permasalahan dan sampai saat ini masih belum dapat diatasi sepenuhnya. Terutama pada kawasan kumuh yang merupakan kawasan rawan air bersih sehingga masyarakat mengalami kesulitan untuk mendapatkan air bersih. Banyaknya kawasan kumuh di Kab. Lingga menjadi permasalahan tersendiri untuk perencanaan penyediaan air bersih, dari permasalah tersebut dirancanglah suatu sistem yang bertujuan untuk menentukan kawasan prioritas penyediaan air bersih dengan menerapkan metode fuzzy multi criteria decision making dalam perencanaan kawasan prioritas penyediaan air bersih, mendapatkan kawasan yang nilai total integral tertinggi yaitu Marok Tua dengan nilai $\alpha 0$ adalah $0,34375, \alpha 0,5$ adalah $0,51875, \alpha 1$ adalah 0,69375 .

Kata kunci: penyediaan, prioritas, fuzzy, air bersih, kriteria

\section{Pendahuluan}

Fuzzy multi criteria decision making adalah suatu metode pengambilan keputusan yang bertujuan untuk menetapkan alternatif keputusan terbaik dari sejumlah alternatif berdasarkan beberapa kriteria tertentu yang akan menjadi bahan pertimbangan [1]. Sangat tepat untuk diimplementasikan pada kasus dengan semua alternatif yang memiliki sejumlah kriteria yang masing-masing memiliki nilai nominal dan masing-masing kriteria memiliki bobot yang dapat dimanfaatkan sebagai sarana pembanding [2].

Dalam penerapannya, fuzzy multi criteria decision making dapat digunakan juga pada permasalahan menetukan lokasi promosi produk, yang memiliki empat kriteria dan tiga alternatif lokasi dan mendapatkan hasil lokasi yang tepat untuk promosi produk [3]. Dalam menetukan lokasi perumahan dapat juga menggunakan FMDCM, hasil yang diperoleh yaitu mampu memberikan hasil yang cepat, tepat dan akurat bagi konsumen dalam menentukan lokasi perumahan [4]. Fuzzy multi criteria decision 
making dapat juga dikombinasikan dengan algoritma peramalan indeks musim dalam memprediksi kecocokan tanaman pangan di Salatiga [5].

Untuk perencanaan kawasan prioritas penyediaan air bersih memiliki lima kriteria sebagai pertimbangan, (1) kepadatan penduduk; (2) keluarga miskin; (3) Sambungan rumah yang belum tersedia; (4) kebutuhan air; (5) rencana anggaran biaya perkawasan. Dan memiliki sebelas kawasan kumuh yang terdapat pada Kabupaten lingga Provinsi Kepulauan Riau sebagai alternatif.

Berdasarkan Keputusan Menteri Kesehatan Republik Indonesia Nomor 1405/MENKES/SK/XI/2002, bahwa air bersih adalah air yang dipergunakan untuk keperluan sehari-hari dan kualitasnya memenuhi persyaratan kesehatan air bersih sesuai dengan peraturan perundang-undangan yang berlaku dan dapat diminum apabila dimasak. Dan berdasarkan Peraturan Menteri (PERMEN) Pekerjaan Umum (PU) No.14/PRT/M/2010 Tentang Pelayanan Minimal Bidang PU dan Penataan Ruang, BAB II SPM Bidang PU dan Penataan Ruang Daerah Kabupaten/Kota Pasal 5 No.2C menyebutkan "Tersedianya akses air minum yang aman melalui Sistem Penyediaan Air Minum dengan jaringan perpipaan dan bukan jaringan perpipaan terlindungi dengan kebutuhan pokok minimal 60liter/orang/hari”.

Pelaksanaan kegiatan penyediaan air bersih harus mengacu pada dasar hukum yang berlaku. Undang-undang No.7 Tahun 2004 Tentang Sumber Daya Air, didalamnya juga mengatur beberapa hal mengenai penyediaan air bersih. Sumber air merupakan salah satu komponen utama yang ada pada suatu sistem penyediaan air bersih, karena tanpa sumber air maka suatu sistem penyediaan air bersih tidak akan berfungsi [6].

\section{METODE PENELITIAN}

Penelitian dilakukan melalui langkahlangkah sebagai berikut :

\section{A. Reprentasi Masalah}

Pada bagian, ada 3 aktivitas yang harus dilakukan, adalah:
1. Identifikasi tujuan dan kumpulan alternatif keputusannya;

Tujuan keputusan dapat direpresentasikan dengan menggunakan bahasa alami atau nilai numeris sesuai dengan karakteristik dari masalah tersebut Jika ada $\mathrm{n}$ alternatif keputusan dari suatu masalah, maka alternatif-alternatif tersebut dapat ditulis sebagai $A=\{A i \mid i=1,2, \ldots, n\}$.

2. Identifikasi kumpulan kriteria;

Jika ada $\mathrm{k}$ adalah kriteria, maka dapat dituliskan $\mathrm{C}=\{\mathrm{Ct} \mid \mathrm{t}=1,2, \ldots, \mathrm{k}\}$.

3. Membangun stuktur hirarki dari masalah tersebut berdasarkan pertimbanganpertimbangan tertentu.

\section{Struktur Hirarki dapat dilihat pada Gambar 1}

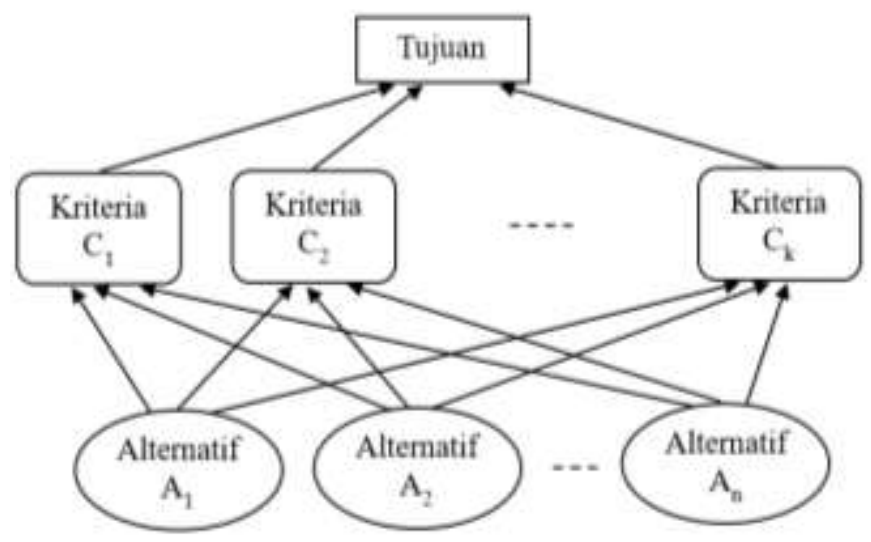

Gambar 1. Struktur Hirarki

\section{B. Evaluasi Himpunan Fuzzy}

Pada bagian ini, terdapat beberapa aktivitas yang harus dilakukan, adalah

1. Memilih himpunan rating untuk bobotbobot kriteria, dan derajat kecocokan setiap alternatif dengan kriterianya. Himpunan rating terdiri atas 3 elemen, adalah :

a. Variabel linguistik $(\mathrm{x})$ yang merepresentasikan bobot kriteria, dan derajat kecocokan setiap alternatif dengan kriterianya;

b. $\mathrm{T}(\mathrm{x})$ yang merepresentasikan rating dari variabel linguistik;

c. Fungsi keanggotaan yang berhubungan dengan setiap elemen dari $\mathrm{T}(\mathrm{x})$. Misal, 


$$
\begin{array}{ll}
\text { Sangat Rendah } & =\mathrm{SR}=(0,0,0.25) \\
\text { Rendah } & =\mathrm{R}=(0,0.25,0.5) \\
\text { Sedang } & =\mathrm{S}=(0.25,0.5,0.75) \\
\text { Tinggi } & =\mathrm{T}=(0.5,0.75,1) \\
\text { Sangat Tinggi } & =\mathrm{ST}=(0.75,1,1)
\end{array}
$$

rating untuk bobot pada variabel paenting untuk suatu kriteria di definisikan sebagai : $\mathrm{T}$ (penting) $=\{$ Sangat Rendah, Rendah, Cukup, Tinggi, Sangat Tinggi\}. Setelah menentukan himpunan rating, maka harus ditentukan fungsi keanggotaannya untuk setiap rating dengan menggunakan fungsi segitia. Misal $W_{t}$ adalah bobot untuk kriteria $C_{t}$; dan $S_{i t}$ adalah rating fuzzy untuk derajat kecocokan alternatif keputusan $A_{i}$ dengan kriteria $C_{t ;}$ dan $F_{i}$ adalah indek kecocokan fuzzy dari alternatif $A_{i} \quad$ yang merepresentasikan derajat kecocokan alternatif keputusan dengan kriteria keputusan yang diperoleh dari hasil agregasi $S_{i t}$ dan $W_{t}$.

2. Menentukan bobot-bobot setiap rating dari himpunan rating derajat kepentingan setiap kriteria dan derajat kecocokan setiap alternatif dengan kriterianya. Bobot untuk setiap rating ditentukan dengan menggunakan fungsi keanggotaan bilangan fuzzy . Adapun fungsi keanggotaan bilangan fuzzy yang digunakan adalah fungsi bilangan fuzzy segitiga. Gambar fungsi keanggotaan fuzzy segitiga dapat dilihat pada Gambar 2:

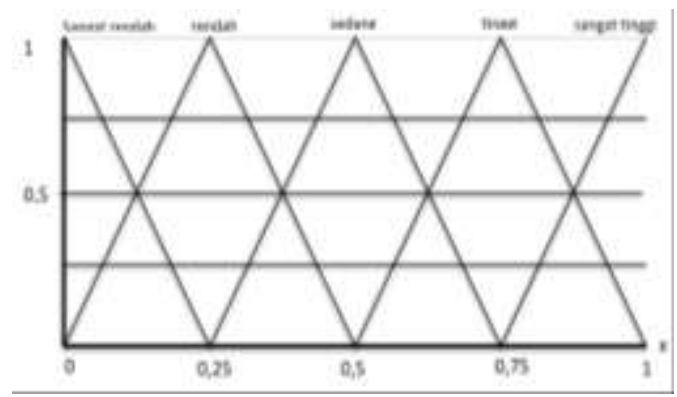

Gambar 2. Fungsi Keanggotaan Segitiga
Dengan rentang yang digunakan adalah:

Pemberian bobot untuk variabel yang memiliki range nilai adalah dengan cara mengkoversikan variabel tersebut ke dalam bilangan fuzzy.

3. Mengelompokan bobot-bobot kriteria, dan derajat kecocokan setiap alternatif dan kriterianya dengan metode mean. Penggunaan Operator mean, $F_{i}$ dirumuskan pada Persamaan (1) sebagai berikut:

$F_{i}=\left(\frac{1}{k}\right)\left[\left(S_{i t} \times W_{t}\right)+\left(S_{i t} \times W_{t}\right)+\cdots+\left(S_{i t} \times W_{t}\right)(1)\right.$

\section{Dimana :}

$F_{i} \quad:$ Indeks kecocokan fuzzy dari alternatif $A_{i}$

yang mempresentasikan derajat kecocokan alternatif keputusan dengan kriteria keputusan yang diperoleh dari hasil agregrasi (pengelompokan) $S_{i t}$ dan $W_{i t}$

$S_{i t} \quad$ : Bobot rating fuzzy untuk derajat kecocokanalternatif keputusan $A_{i}$ dengan kriteria $C_{t}$

$W_{t} \quad$ : Bobot rating fuzzy untuk derajat kepentingan $C_{t}$

$k \quad:$ Banyaknya Kriteria

Dengan cara mensubsitusikan $S_{i t}$ dan $W_{t}$ dengan bilangan fuzzy segitiga, $S_{i t}=$ $\left(O_{i t}, P_{i t}, Q_{i t}\right)$; dan $\mathrm{W}_{\mathrm{t}}=\left(a_{t}, b_{t}, c_{t}\right)$; maka $F_{t}$ dapat didekati sebagai Persamaan (2.2):

$F_{t}=\left(Y_{i}, Q_{i_{i}} Z_{i}\right)$

Dengan $\left(Y_{i}, Q_{i}, Z_{i}\right)$ seperti pada Persamaan (3), (4), dan (5): 


$$
\begin{aligned}
& Y_{i}=\left(\frac{1}{k}\right) \sum_{t=1}^{k}\left(o_{i t}, a_{i}\right) \\
& Q_{i}=\left(\frac{1}{k}\right) \sum_{t=1}^{k}\left(p_{i t}, b_{i}\right) \\
& Z_{i}=\left(\frac{1}{k}\right) \sum_{t=1}^{k}\left(q_{i t}, c_{i}\right)
\end{aligned}
$$

Dimana, $\mathrm{i}=1,2,3, \ldots, \mathrm{n}$.

Keterangan :

$Y_{i}, Q_{i_{i}} Z_{i} \quad$ : Bilangan fuzzy segitiga dari alternatif $A_{i}$ hasil agregasi dari $S_{i t}$ dan $W_{t}$

$o_{i t}, p_{i t_{2}} q_{i t}:$ Bilangan fuzzy segitiga untuk derajat kecocokan alternatif keputusan $A_{i}$ dengan kriteria $C_{t}$

$a_{i}, b_{i_{i}} c_{\tilde{i}}$ : Bilangan fuzzy segitiga untuk bobot kriteria $C_{t}$

$i \quad$ : Alternatif ke

$t \quad$ : Bobot ke

$k \quad$ : Banyak kriteria

\section{Seleksi Alternatif Optimal}

1. Memprioritaskan alternatif keputusan berdasarkan hasil pengelompokan untuk proses perangkingan alternatif keputusan dengan menggunakan metode nilai total interal. Misalkan $\mathrm{F}$ adalah bilangan fuzzy segitiga, $F=(a, b, c)$, maka nilai total integral dapat dirumuskan sebagai Persamaan (2.9) berikut:

$I_{t}^{a}(F)=\frac{1}{2}(\alpha Z+Q+(1-\alpha) Y)$

Keterangan :

$I_{T}^{a}(F) \quad$ : Nilai total integral

$y, q, z \quad$ : Bilangan fuzzy segitiga dari hasil persamaan (3), (4), (5) $\alpha \quad$ : Indeks keoptimisan yang mempresentasikan derajat keoptimis-an

Bagi pengambil keputusan ( $0 \leq \alpha \geq 1$ ).

Apabila nila $\alpha$ semakin besar maka mengidetifikasikan bahwa derajat keoptimisannya semakin besar.

Nilai $\alpha$ adalah indeks ke-optimisan yang merepresentasikan derajat keoptimisan bagi pengambil keputusan $(0 \leq \alpha \leq 1)$. Apabila nilai $\alpha$ semakin besar mengindentifikasikan bahwa derajat keoptimisannya semakin besar.

2. Memilih alternatif keputusan dengan prioritas tertinggi sebagai alternatif yang optimal.

\section{HASIL DAN PEMBAHASAN}

Ada 11 kawasan yang akan menjadi alternatif untuk perencanaan kawasan prioritas penyediaan air bersih, ditunjukan pada Tabel 1 berikut:

Tabel 1. Alternatif Nama Kawasan

\begin{tabular}{cc}
\hline Alternatif & Nama Kawasan \\
\hline $\mathbf{1}$ & Dabo Lama \& Batu Bedaun \\
$\mathbf{2}$ & Melukap Laut \\
$\mathbf{3}$ & Pancur dan Duara \\
$\mathbf{4}$ & Marok Tua \\
$\mathbf{6}$ & Panggak Laut \\
$\mathbf{7}$ & Nerekeh \\
$\mathbf{8}$ & Sei Pinang \\
$\mathbf{9}$ & Rejai \\
$\mathbf{1 0}$ & Senayang \\
$\mathbf{1 1}$ & Budus \\
\hline
\end{tabular}


Ada 5 atribut (kriteria) pengambil keputusan, yang ditunjukan pada Tabel 2, berikut:

Tabel 2 Kriteria

\begin{tabular}{cc}
\hline Variabel & Kriteria \\
$\left(\mathbf{C}_{\mathbf{t}}\right)$ & \\
\hline $\mathbf{C}_{\mathbf{1}}$ & Kepadatan Penduduk \\
$\mathbf{C}_{\mathbf{2}}$ & Keluarga Miskin \\
$\mathbf{C}_{\mathbf{3}}$ & Kebutuhan Air \\
$\mathbf{C}_{\mathbf{4}}$ & Sambungan Rumah Yang Belum \\
& Tersedia \\
$\mathbf{C}_{\mathbf{5}}$ & Rencana Anggaran Biaya Perkawasan \\
\end{tabular}

\section{Langkah 1: Representasi masalah}

a. Tujuan keputusan ini adalah mencari kawasan prioritas untuk penyediaan air bersih berdasarkan kriteria-kriteria tertentu. Ada 11 alternatif kawasan yang diberikan adalah $\mathrm{A}=\{\mathrm{A} 1, \mathrm{~A} 2, \mathrm{~A} 3 \ldots . . . \mathrm{A} 11\}$ seperti yang ditunjukan pada Tabel. 1 diatas.

b. Ada 5 kriteria keputusan yang diberikan, yaitu: $\mathrm{C}=\{\mathrm{C} 1, \mathrm{C} 2, \mathrm{C} 3, \mathrm{C} 4, \mathrm{C} 5\}$

c. Struktur hirarki masalah tersebut seperti terlihat pada Gambar 3.

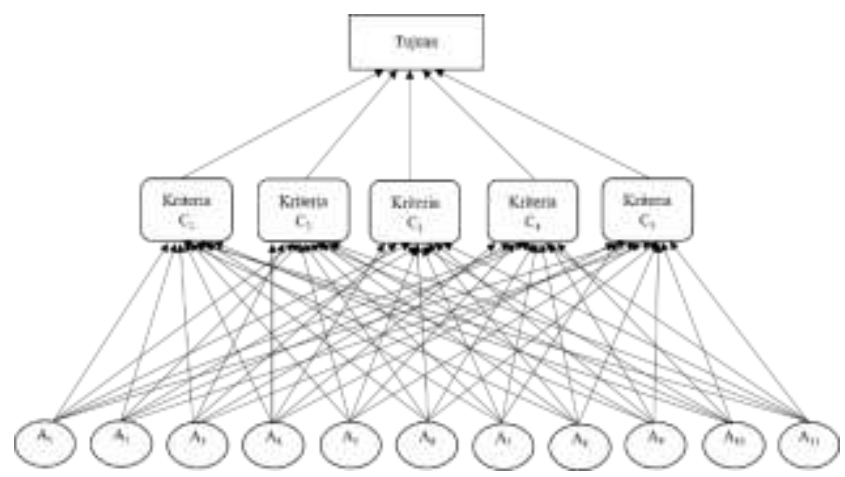

Gambar 3. Struktur Hirarki

\section{Langkah 2: Evaluasi himpunan fuzzy dari alternatif-alternatif keputusan}

a. Variabel-variabel linguistik yang merepresentasikan bobot kepentingan untuk setiap kriteria, adalah: $\mathrm{T}$ (kepentingan) $\mathrm{W}=$ $\{\mathrm{R}, \mathrm{S}, \mathrm{T}$,$\} dengan \mathrm{R}=$ Rendah; $\mathrm{S}=$ Sedang; $\mathrm{T}=$ Tinggi. b. Sedangkan derajat kecocokan alternatifalternatif dengan kriteria keputusan adalah: $\mathrm{T}$ (kecocokan) $\mathrm{S}=\{\mathrm{R}, \mathrm{S}, \mathrm{T}$,$\} dengan \mathrm{R}=$ Rendah; $\mathrm{S}=$ Sedang; $\mathrm{T}=$ Tinggi.

Fungsi keanggotaan untuk setiap elemen direprentasikan dengan menggunakan bilangan fuzzy segitiga sebagai berikut:

$$
\begin{aligned}
\text { - } \mathrm{R} & =(0,0.25,0.5) \\
\text { - } \mathrm{S} & =(0.25,0.5,0.75) \\
\text { - } \mathrm{T} & =(0.5,0.75,1)
\end{aligned}
$$

Rating untuk setiap kriteria keputusan yang diberikan oleh pengambil keputusan seperti terlihat pada Tabel 3. Sedangkan derajat kecocokan kriteria keputusan dan alternatif seperti terlihat pada Tabel 4.

Tabel 3. Rating Kepentingan

\begin{tabular}{cccccc}
\hline Kriteria & $\mathbf{C}_{1}$ & $\mathbf{C}_{2}$ & $\mathbf{C}_{3}$ & $\mathbf{C}_{4}$ & $\mathbf{C}_{5}$ \\
& & & & & \\
\hline Rating Kepentingan & $\mathrm{S}$ & $\mathrm{T}$ & $\mathrm{T}$ & $\mathrm{T}$ & $\mathrm{S}$
\end{tabular}

Tabel 4. Rating Kecocokan

\begin{tabular}{cccccc}
\hline \multirow{2}{*}{ Alternatif } & \multicolumn{5}{c}{ Rating Kecocokan } \\
& $\mathrm{C}_{1}$ & $\mathrm{C}_{2}$ & $\mathrm{C}_{3}$ & $\mathrm{C}_{4}$ & $\mathrm{C}_{5}$ \\
\hline $\mathbf{A}_{\mathbf{1}}$ & $\mathrm{S}$ & $\mathrm{S}$ & $\mathrm{T}$ & $\mathrm{R}$ & $\mathrm{R}$ \\
$\mathbf{A}_{2}$ & $\mathrm{R}$ & $\mathrm{R}$ & $\mathrm{T}$ & $\mathrm{R}$ & $\mathrm{R}$ \\
$\mathbf{A}_{3}$ & $\mathrm{~S}$ & $\mathrm{R}$ & $\mathrm{T}$ & $\mathrm{R}$ & $\mathrm{R}$ \\
$\mathbf{A}_{4}$ & $\mathrm{R}$ & $\mathrm{S}$ & $\mathrm{T}$ & $\mathrm{R}$ & $\mathrm{R}$ \\
$\mathbf{A}_{5}$ & $\mathrm{~T}$ & $\mathrm{~T}$ & $\mathrm{~T}$ & $\mathrm{~T}$ & $\mathrm{R}$ \\
$\mathbf{A}_{6}$ & $\mathrm{R}$ & $\mathrm{R}$ & $\mathrm{R}$ & $\mathrm{R}$ & $\mathrm{R}$ \\
$\mathbf{A}_{7}$ & $\mathrm{R}$ & $\mathrm{R}$ & $\mathrm{R}$ & $\mathrm{R}$ & $\mathrm{R}$ \\
$\mathbf{A}_{\mathbf{8}}$ & $\mathrm{R}$ & $\mathrm{S}$ & $\mathrm{S}$ & $\mathrm{R}$ & $\mathrm{R}$ \\
$\mathbf{A}_{9}$ & $\mathrm{R}$ & $\mathrm{R}$ & $\mathrm{R}$ & $\mathrm{R}$ & $\mathrm{R}$ \\
$\mathbf{A}_{10}$ & $\mathrm{R}$ & $\mathrm{R}$ & $\mathrm{T}$ & $\mathrm{R}$ & $\mathrm{R}$ \\
$\mathrm{A}_{11}$ & $\mathrm{~T}$ & $\mathrm{R}$ & $\mathrm{R}$ & $\mathrm{R}$ & $\mathrm{R}$ \\
\hline
\end{tabular}


c. Mengelompokan bobot-bobot kriteria, dan derajat kecocokan setiap alternatif dan kriterianya dengan mensubstitusikan bilangan fuzzy segitiga ke setiap variabel linguisttik dengan menggunakan persamaan (1) sampai dendan mendapatkan hasil yang ditunjukan pada Tabel 5 berikut.

\section{Langkah 3: Menyeleksi alternatif yang optimal}

a. Dengan mensubstitusikan indeks kecocokan fuzzy pada Tabel 5, ke persamaan (6), dan dengan mengambil derajat keoptimisan $\alpha=$ 0 (tidak optimis), $\alpha=0,5$ dan $\alpha=1$ (sangat optimis), maka akan diperoleh nilai total integral seperti terlihat pada Tabel 6 .

b. Dari Tabel 6 terlihat bahwa alternatif A5 memiliki nilai total integral terbesar berapapun derajat keoptimisannya, sehingga kawasan Marok Tua akan terpilih sebagai kawasan prioritas yang optimal untuk penyediaan air bersih.

Tabel 5. Indeks Kecocokan Fuzzy

\begin{tabular}{ccccccccc}
\hline \multirow{2}{*}{ Alternatif } & \multicolumn{3}{c}{ Rating Kecocokan } & \multicolumn{4}{c}{ Indeks Kecocokan Fuzzy } \\
& $\mathbf{C}_{\mathbf{1}}$ & $\mathbf{C}_{2}$ & $\mathbf{C}_{\mathbf{3}}$ & $\mathbf{C}_{\mathbf{4}}$ & $\mathbf{C}_{\mathbf{5}}$ & $\mathbf{Y}$ & $\mathbf{Q}$ & $\mathrm{Z}$ \\
\hline $\mathbf{A}_{\mathbf{1}}$ & $\mathrm{S}$ & $\mathrm{S}$ & $\mathrm{T}$ & $\mathrm{R}$ & $\mathrm{R}$ & 0,0875 & 0,3000 & 0,6375 \\
$\mathbf{A}_{\mathbf{2}}$ & $\mathrm{R}$ & $\mathrm{R}$ & $\mathrm{T}$ & $\mathrm{R}$ & $\mathrm{R}$ & 0,0500 & 0,2375 & 0,5500 \\
$\mathbf{A}_{\mathbf{3}}$ & $\mathrm{S}$ & $\mathrm{R}$ & $\mathrm{T}$ & $\mathrm{R}$ & $\mathrm{R}$ & 0,0625 & 0,2625 & 0,5875 \\
$\mathbf{A}_{\mathbf{4}}$ & $\mathrm{R}$ & $\mathrm{S}$ & $\mathrm{T}$ & $\mathrm{R}$ & $\mathrm{R}$ & 0,075 & 0,275 & 0,60 \\
$\mathbf{A}_{\mathbf{5}}$ & $\mathrm{T}$ & $\mathrm{T}$ & $\mathrm{T}$ & $\mathrm{T}$ & $\mathrm{R}$ & 0,2000 & 0,4875 & 0,9000 \\
$\mathbf{A}_{\mathbf{6}}$ & $\mathrm{R}$ & $\mathrm{R}$ & $\mathrm{R}$ & $\mathrm{R}$ & $\mathrm{R}$ & 0 & 0,1625 & 0,4500 \\
$\mathbf{A}_{\mathbf{7}}$ & $\mathrm{R}$ & $\mathrm{R}$ & $\mathrm{R}$ & $\mathrm{R}$ & $\mathrm{R}$ & 0 & 0,1625 & 0,4500 \\
$\mathbf{A}_{\mathbf{8}}$ & $\mathrm{R}$ & $\mathrm{S}$ & $\mathrm{S}$ & $\mathrm{R}$ & $\mathrm{R}$ & 0,0500 & 0,2375 & 0,5500 \\
$\mathbf{A}_{9}$ & $\mathrm{R}$ & $\mathrm{R}$ & $\mathrm{R}$ & $\mathrm{R}$ & $\mathrm{R}$ & 0 & 0,1625 & 0,4500 \\
$\mathbf{A}_{\mathbf{1 0}}$ & $\mathrm{R}$ & $\mathrm{R}$ & $\mathrm{T}$ & $\mathrm{R}$ & $\mathrm{R}$ & 0,0500 & 0,2375 & 0,5500 \\
$\mathbf{A}_{\mathbf{1 1}}$ & $\mathrm{T}$ & $\mathrm{R}$ & $\mathrm{R}$ & $\mathrm{R}$ & $\mathrm{R}$ & 0,0250 & 0,2125 & 0,5250 \\
\hline
\end{tabular}


Table 6. Nilai Total Integer

\begin{tabular}{ccccc}
\hline $\begin{array}{c}\text { Alternatif } \\
\left(\mathbf{A}_{\mathbf{n}}\right)\end{array}$ & Nama Kawasan & \multicolumn{3}{c}{ Nilai Total Integral } \\
\hline $\mathbf{A}_{\mathbf{1}}$ & Dabo lama dan Batu bedaun & 0,19375 & 0,33125 & 0,46875 \\
$\mathbf{A}_{\mathbf{2}}$ & Melukap Laut & 0,14375 & 0,26875 & 0,39375 \\
$\mathbf{A}_{\mathbf{3}}$ & Dabo & 0,16250 & 0,29375 & 0,42500 \\
$\mathbf{A}_{\mathbf{4}}$ & Pancur dan Duara & 0,17500 & 0,30625 & 0,43750 \\
$\mathbf{A}_{\mathbf{5}}$ & Marok Tua & $\mathbf{0 , 3 4 3 7 5}$ & $\mathbf{0 , 5 1 8 7 5}$ & $\mathbf{0 , 6 9 3 7 5}$ \\
$\mathbf{A}_{\mathbf{6}}$ & Panggak Laut & 0,08125 & 0,19375 & 0,30625 \\
$\mathbf{A}_{\mathbf{7}}$ & Nerekeh & 0,08125 & 0,19375 & 0,30625 \\
$\mathbf{A}_{\mathbf{8}}$ & Sungai Pinang & 0,14375 & 0,26875 & 0,39375 \\
$\mathbf{A}_{\mathbf{9}}$ & Rejai & 0,08125 & 0,19375 & 0,30625 \\
$\mathbf{A}_{\mathbf{1 0}}$ & Senayang & 0,14375 & 0,26875 & 0,39375 \\
$\mathbf{A}_{\mathbf{1 1}}$ & Budus & 0,11875 & 0,24375 & 0,36875 \\
\hline
\end{tabular}

\section{KESIMPULAN}

Berdasarkan hasil dan pembahasan yang telah lakukan dalam pnelitian ini, maka didapatkan kesimpulan bahwa metode fuzzy multi criteria decison making dapat diterapkan dalam perencanaan kawasan prioritas penyediaan air bersih dan menghasilkan Alternatif A5 Kawasan Marok Tua dengan nilai total integral tertinggi yaitu $\boldsymbol{\alpha 0}$ adalah $\mathbf{0 , 3 4 3 7 5}$, $\alpha 0,5$ adalah $0,51875, \alpha 1$ adalah 0,69375 sebagai kawasan prioritas yang optimal penyediaan air bersih.

\section{REFERENSI}

[1] Kusumadewi, S., dan Guswaludin, I., 2005. Fuzzy Multi-Criteria Decision Making. Jurnal Media Informatika, Vol. 3 (No.1), 25-39.

[2] Salim, Y., 2015. Penerapan Fuzzy Multi Criteria Decision Making Untuk Menentukan Pemberian Beasiswa. Seminar Nasional Teknologi Informasi dan Multimedia 2015.
[3] Kahar, N., dan Fitri , N., 2011. Aplikasi Metode Fuzzy Multi Criteria Decision Making (FMCDM) Untuk Optimalisasi Penentuan Lokasi Promosi Produk. Jurnal Seminar Nasional Aplikasi Teknologi Informasi.

[4] Maryaningsih, dan Mesterjon., 2012. Implementasi Metode Fuzzy Multi Criteria Decision Making (FMCDM) Untuk Optimalisasi Penentuan Lokasi Perumahan. Jurnal Media Infotama, Vol. 8 (No. 1), 62-89.

[5] Lissa, R., Tanaamah, A. R., dan Wowor, A. D., 2015. Kombinasi Algoritma Peramalam Indeks Musim Dan Pengembangan Fuzzy-MCDM Dalam Memperediksi Kecocokan Tanaman Pangan Di Salatiga. Jurnal Seminar Nasional Sistem Informasi Indonesia.

[6] Wulan, A. I., 2005. Kualitas Air Bersih Untuk Pemenuhan Kebutuhan Rumah Tangga Di Desa Pesarean Kecamatan Adiwerna Kabupaten Tegal. Skripsi, Universitas Negeri Semarang, Semarang. 